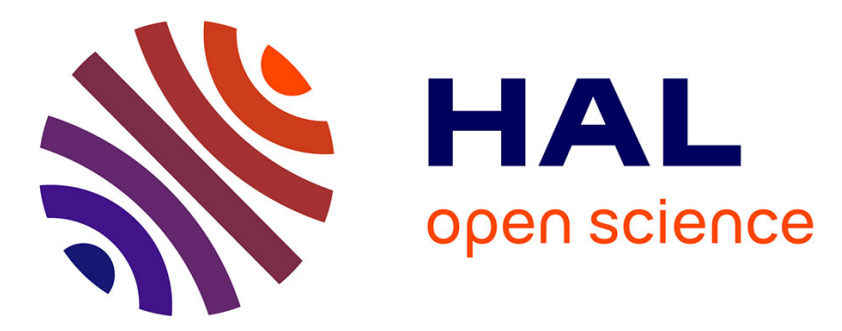

\title{
Contact, Perspective Taking, and Anxiety as Predictors of Stereotype Endorsement, Explicit Attitudes, and Implicit Attitudes
}

\author{
Christopher L. Aberson, Sarah C. Haag
}

\section{To cite this version:}

Christopher L. Aberson, Sarah C. Haag. Contact, Perspective Taking, and Anxiety as Predictors of Stereotype Endorsement, Explicit Attitudes, and Implicit Attitudes. Group Processes and Intergroup Relations, 2007, 10 (2), pp.179-201. 10.1177/1368430207074726 . hal-00571645

\section{HAL Id: hal-00571645 \\ https://hal.science/hal-00571645}

Submitted on 1 Mar 2011

HAL is a multi-disciplinary open access archive for the deposit and dissemination of scientific research documents, whether they are published or not. The documents may come from teaching and research institutions in France or abroad, or from public or private research centers.
L'archive ouverte pluridisciplinaire HAL, est destinée au dépôt et à la diffusion de documents scientifiques de niveau recherche, publiés ou non, émanant des établissements d'enseignement et de recherche français ou étrangers, des laboratoires publics ou privés. 


\title{
Contact, Perspective Taking, and Anxiety as Predictors of Stereotype Endorsement, Explicit Attitudes, and Implicit Attitudes
}

\author{
Christopher L. Aberson \\ Humboldt State University
}

\author{
Sarah C. Haag \\ University of Iowa
}

\begin{abstract}
We proposed a model of intergroup contact wherein contact promotes understanding of outgroup perspectives, perspective taking relates to reduced intergroup anxiety that in turn is associated with lessened stereotyping and more positive intergroup attitudes. Additionally, we examined if implicit attitudes followed this model or were directly impacted by contact. White undergraduates $(n=153)$ completed measures of contact, perspective taking, intergroup anxiety, stereotype endorsement, and implicit and explicit intergroup attitudes. Our model fitted the data well but explained explicit attitudes and stereotyping better than implicit attitudes. Supporting an environmental association interpretation, contact was the only significant predictor of implicit attitudes. Findings support a dual-process model wherein implicit and explicit attitudes represent separate constructs and support the value of contact in improving intergroup attitudes.
\end{abstract}

KEYWORDS contact, evaluative associations, explicit attitudes, implicit attitudes

INTERGROUP prejudice is a well-established phenomenon. Put simply, individuals tend to evaluate members of other groups (e.g. ethnic, racial, religious groups) less favorably than members of their own groups. Several theories address factors that reduce prejudice. The current study applies aspects of intergroup contact theory (Allport, 1954; Pettigrew, 1998), integrated threat theory (W. G. Stephan \& Stephan, 2000), and research on perspective taking (e.g. Galinsky \& Moskowitz, 2000) to an examination of explicit and implicit prejudice.
We propose a model wherein intergroup attitudes are impacted by a three-stage process. Figure 1 presents the general model and Figure 2 extends this model by presenting competing predictions regarding implicit and explicit attitudes. The initial stage is contact. Contact

\footnotetext{
$\overline{\text { Author's note }}$

Address correspondence to Chris Aberson, Department of Psychology, Humboldt State University, Arcata, CA 95521, USA [email: CLA18@humboldt.edu]
} 
experiences relate to improved understanding of the perspectives of outgroup members. Improved perspective taking relates to reduced intergroup anxiety, which lessens stereotype endorsement and reduces negative intergroup attitudes. As the literature examining the impact of contact, perspective taking, and anxiety on stereotyping and explicit attitudes is more abundant, we first discuss these relationships. Next, we address how these variables potentially impact implicit attitudes and discuss the implicit/explicit attitude distinction.

\section{Contact}

Our model, as represented in Figure 1, begins with intergroup contact. A large body of research establishes the benefits of intergroup contact on attitudes toward ethnic minorities and other outgroups. The bulk of this research focuses on the relationship between contact and explicit measures of bias (e.g. social distance, affect, stereotype endorsement). A metaanalysis examining over 200 studies provided convincing support for the value of contact, finding moderate to strong relationships between contact with outgroup members and more positive attitudes toward the outgroup as well as reduced endorsement of negative outgroup stereotypes (Pettigrew \& Tropp, 2000).

We conceptualize contact as a distal rather than a proximal predictor of attitudes (e.g. W.G. Stephan \& Stephan, 2000). A proximal predictor directly impacts the construct of interest, whereas a distal predictor's impact is mediated by proximal variables. As a distal predictor, we propose contact affects attitudes and stereotypes about outgroups by influencing anxiety and perspective taking.

We examine contact in terms of quantity, quality, and their interaction. Allport's (1954) contact hypothesis focused primarily on what we term quality of contact. The contact hypothesis specifies that contact with outgroup members is beneficial to attitudes about the outgroup when individuals have equal status, common goals, are in a cooperative or interdependent setting, and have support from authorities. Contact meeting these conditions improves intergroup attitudes more than contact that does not (Pettigrew, 1998). Though contact quality plays an important role in improving intergroup attitudes, even when contact conditions are not ideal, contact is beneficial to intergroup attitudes. Meta analytic results demonstrate significant, albeit, smaller effects for contact that does not meet optimal conditions (i.e. contact quantity; Pettigrew \& Tropp, 2000).

Studies demonstrating the impact of contact on attitudes are too numerous to review here. However, a recent investigation informs our approach through examination of the multiplicative combination (i.e. interaction) of quality and quantity of contact. In this study, the interaction between contact quality and quantity predicted several aspects of attitudes toward an outgroup that the main effects of quality and quantity could not predict (Voci \& Hewstone, 2003). The interaction was such that the combination of more frequent and better quality contact was related to the most positive intergroup attitudes. Though the authors did not specifically address the issue, we suggest the following hierarchy regarding quality and quantity combinations. We expect that contact that is both high in quantity and high in quality has the most positive impact on intergroup attitudes. Contact that combines high quality and low quantity should also positively impact attitudes, though not as strongly as frequent high quality contact. We expect low quality-low quantity contact to exert a negative impact on attitudes; however, low quality-high quantity should promote the least positive attitudes. Combined with meta analytic results, this suggests that not only are contact quality and quantity important individually, but the interaction between them also improves prediction of attitudes.

Throughout this article, we distinguish between contact quantity, contact quality, and their interaction as predictors of variables in our model. However, quantity and quality may not be independent. Studies examining both quality and quantity of contact demonstrate that more contact experiences relate to better perceptions of contact quality (Brown, Maras, Masser, Vivian, \& Hewstone, 2001; Voci \& Hewstone, 2003). This implies that the pairings in the hierarchy above 
are not equally likely. Given that high quantity contact relates to better quality perceptions, experiencing high quantity and low quality contact in combination may be unlikely.

Although the positive impact of contact on attitudes is well documented, there is less research examining how contact works. As shown in Figure 1, we propose that contact influences perspective taking, which in turn influences intergroup anxiety, and intergroup anxiety influences attitudes and stereotype endorsement. Thus, we propose that contact works by influencing mediating variables, and describe the rationale for this model below.

\section{Perspective taking}

One mechanism that we propose to mediate contact influences on attitudes is the ability to understand outgroup perspectives. In defining perspective taking we focus on cognitive empathy, understanding the perspectives of others (Davis, 1994). Another form of empathy, known as emotional empathy, involves experiencing similar emotional responses to the experiences of others. Emotional empathy comprises parallel empathy, experiencing the same emotions as another person and reactive empathy, an emotional response to the experience of another person (Finlay \& Stephan, 2000). Though the focus of the current study is cognitive empathy, we discuss studies examining several types of empathy below as many studies incorporate perspective taking in conjunction with other forms of empathy (e.g. Galinsky \& Moskowitz, 2000) and because perspective taking may lead to emotional empathy (Isen, 1984).

At a general level, empathy for outgroup members results in improved attitudes toward outgroups (W. G. Stephan \& Finlay, 1999). A series of studies demonstrated that participants who empathized with members of stigmatized groups such as people with AIDS, the homeless, and murderers, demonstrated improved attitudes toward members of the group (Batson etal., 1997). Participants who imagined themselves experiencing the emotions of an African American while reading scenarios depicting discrimination against an African American target demonstrated improved attitudes toward African Americans (Finlay \& Stephan, 2000). Relevant to cognitive empathy, participants instructed to take the perspective of an African American target evaluated the target more favorably and demonstrated more positive attitudes toward African Americans in general (Vescio, Sechrist, \& Paolucci, 2003).

Perspective taking also reduces stereotype endorsement. In a series of studies examining stereotypes about the elderly, participants instructed to imagine a day in the life of an elderly

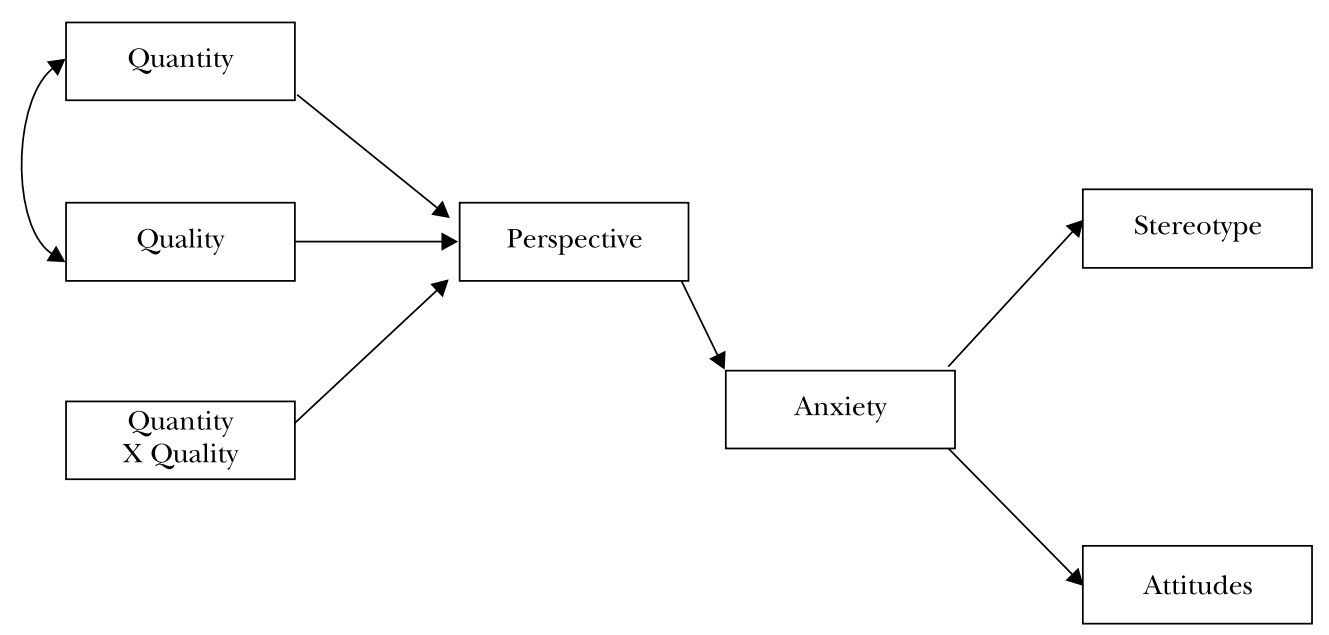

Figure 1. General path model predicting stereotyping and attitudes. 
person, described that person less stereotypically and rated them more positively (if the participant had high self-esteem) than participants who did not take the elderly target's perspective (Galinsky \& Ku, 2004; Galinsky \& Moskowitz, 2000). Similarly, individuals who believed they understood their grandparent's points of view demonstrated more positive attitudes toward older adults (Harwood, Hewstone, Paolini, \& Voci, 2005).

Further evidence for the importance of perspective taking in improving intergroup attitudes comes from research on children. A general finding across studies is that prejudice directed at ethnic groups lessens as children become more aware of the perspectives and experiences of these groups (e.g. Black-Gutman \& Hickson, 1996; Doyle \& Aboud, 1995; Quintana, Ybarra, Gonzalez-Doupe, \& De Baessa, 2000). Although it appears that increases in perspective taking represent a stage in cognitive developmental processes (e.g. Selman, 1980), differences in individual levels of perspective taking likely exist.

\section{Contact influences on perspective taking}

Central to our model is the proposition that contact with outgroups promotes perspective taking. The role of contact in improving perspective taking is central to several models of cooperative education (e.g. Johnson \& Johnson, 1989). For example, the 'three C's' model of prejudice reduction posits that interdependent contact and positive intergroup experiences lead to increased understanding of outgroup perspectives (among other benefits) that in turn promote more positive relationships with outgroup members (Johnson \& Johnson, 2000). Consistent with these propositions, a course providing structured interracial dialogs supported that idea that contact improved understanding of outgroup perspectives. Students engaging in face-to-face encounters with outgroup members experienced increases in perspective taking ability, although the effect existed only for individuals who valued the dialogic process (Nagda \& Zúñiga, 2003).

Studies of diversity education also support the claim that contact improves perspective taking. White students with more diversity experiences such as completing diversity courses and attending interethnic dialogs demonstrated higher levels of perspective taking than students with fewer experiences (Gurin, Nagda, \& Lopez, 2004; Study 2). The same authors compared students enrolled in a firstyear diversity education program to a matched group of students who did not enroll. Program participants exhibited greater perspective taking ability than non-participants when measured in their fourth year on campus (Gurin, et al., 2004; Study 1). Similarly, a large-scale study of campus diversity found that students exposed to courses addressing race, ethnicity, and interethnic relationships evidenced a greater ability to understand outgroup perspectives (Gurin, 1999). Taken together, these studies suggest that contact with outgroup members or even exposure to outgroup experiences improves perspective taking.

Though not specifically addressed in these studies, we view diversity education experiences as a form of high quality contact so we expect contact quality to relate to better perspective taking. However, given the association between quality and quantity it is reasonable to suggest that both quantity and the quality by quantity interaction promote perspective taking.

\section{Anxiety}

We propose that contact improves perspective taking which in turn reduces intergroup anxiety and that reductions in anxiety promote more positive attitudes about outgroups. Several relationships, represented in Figure 1, are central to this proposition: the role of intergroup anxiety in promoting stereotype use and negative attitudes toward the outgroup; the relationship between contact and anxiety; and the role of perspective taking in mediating the contact-anxiety relationship.

Evidence that intergroup anxiety is related to negative attitudes toward outgroups is considerable, occurring in evaluations of African Americans (W. G. Stephan et al., 2002), Mexican immigrants in the US (W. G. Stephan, DiazLoving, \& Duran, 2000), Russian immigrants in 
Israel (Bizman \& Yinon, 2001), native Canadians (Corenblum \& Stephan, 2001), prejudice toward people with cancer and AIDS (Berrenberg, Finlay, Stephan, \& Stephan, 2002), reactions to Catholics and Protestants in Northern Ireland (Hewstone, 2002; Paolini, Hewstone, Cairns, \& Voci, 2004), and women's evaluations of men (C. W. Stephan, Stephan, Demitrakis, Yamada, \& Clason, 2000).

Regarding stereotyping, it appears that anxiety distracts attention and promotes reliance on stereotypes to guide judgments (Wilder, 1993). A series of studies suggest a central role for anxiety in promoting stereotype usage. When participants were provided with stereotypes about an outgroup and made to feel anxious, they evaluated counterstereotypical outgroup members as more similar to the outgroup than participants who were not made anxious (Wilder \& Shapiro, 1989). Supporting an attention-based interpretation, when anxious participants focused on the counterstereotypical outgroup member, less assimilation of outgroup stereotypes occurred than when participants focused on stereotypical group members (Wilder \& Shapiro, 1991).

\section{The influence of contact on anxiety}

Given the negative impact of anxiety on intergroup attitudes, several studies examined factors that predict reduced intergroup anxiety. One consistent finding demonstrates that contact with outgroup members relates to reduced intergroup anxiety. For example, improved contact quantity and quality related to less intergroup anxiety toward the French (Brown et al., 2001) and between Hindus and Muslims in Bangladesh (Islam \& Hewstone, 1993). The interaction between quality and quantity of contact predicted reduced anxiety in dealing with African immigrants and immigrant coworkers (Voci \& Hewstone, 2003). Additionally, contact quality is associated with reduced anxiety in several of the studies cited above (e.g. Corenblum \& Stephan, 2001; Hewstone, 2002; Paolini, et al., 2004; C. W. Stephan et al., 2000, Study 3, W. G. Stephan et al., 2000, 2002). These findings suggest that contact quantity, quality, and their interaction relate to reduced intergroup anxiety.
Though contact can reduce intergroup anxiety, it may also be a source of intergroup anxiety. Physiological data indicate that Whites who interacted with African Americans demonstrated increases in responses consistent with threat (Blascovich, Mendes, Hunter, Lickel, \& KowaiBell, 2001; Littleford, Wright, \& Sayoc-Parial, 2005). However, supporting the value of contact quantity in anxiety reduction, participants with frequent contact experiences demonstrated fewer threat responses when interacting with African Americans than those with less frequent contact (Blascovich, et al., 2001).

\section{Perspective taking as a mediator of the contact-anxiety relationship}

Although there exists evidence that positive contact experiences are related to reduced intergroup anxiety, less clear is whether contact directly impacts anxiety or if the relationship is mediated by other factors. Central to our model is the role of perspective taking as a mediator of the contact-anxiety relationship. However, other models and findings suggest a number of potential relationships. For example, anxiety may mediate the contact-perspective taking relationship or anxiety and perspective taking may be correlated with neither mediating the other. We discuss evidence for each relationship below.

Though we propose a mediating role for perspective taking, it is plausible that perspective taking occurs after anxiety reduction. Anxiety reduces cognitive resources (e.g. Easterbrook, 1959) so it is reasonable to suggest that intergroup anxiety negatively impacts the ability to understand outgroup perspectives. Relevant to intergroup interactions, White participants with negative implicit attitudes toward African Americans demonstrated greater cognitive impairment following either interactions with an African American or viewing pictures of African Americans (Richeson et al., 2003; Richeson \& Shelton, 2003). Although the researchers did not specifically address anxiety, it is plausible that prejudiced participants experienced greater anxiety which promoted cognitive impairment. Similarly, a core motives interpretation 
(Fiske, 2004) suggests that individuals focus first on reducing threats such as intergroup anxiety before attempting to understand outgroup perspectives. These data suggest that intergroup anxiety depletes cognitive resources, potentially hindering perspective taking.

There also exists the possibility that perspective taking and anxiety are products of contact but occur simultaneously and possibly independently. Recent reformulations of intergroup contact theory propose central roles for perspective taking and contact but not as mediators of one another (e.g. Kenworthy, Turner, Hewstone, \& Voci, 2005). Given these competing views, we provide tests of three alternative models: one allowing anxiety to mediate the contact-perspective taking relationship, one where both anxiety and perspective taking mediate the contact-attitudes relationship but do not correlate, and one where anxiety and perspective taking mediate the contactattitudes relationship and do correlate.

Our model posits that perspective taking mediates the contact-anxiety relationship. This suggests that contact works by promoting a better understanding of outgroup perspectives. Supporting this view is theorizing regarding social anxiety that posits anxiety results when individuals do not possess clear guidelines regarding how to behave in social interactions (Schlenker \& Leary, 1982) and data suggesting that interracial anxiety results from a lack of social skills necessary to promote a nonprejudiced image (Devine, Evett, \& VasquezSuson, 1996). Beliefs that one understands outgroup perspectives should relate to clearer behavioral guidelines or a better understanding of such guidelines that in turn reduces intergroup anxiety.

Supporting these propositions, participants with worse contact experiences expected negative experiences when interacting with African Americans, and demonstrated greater intergroup anxiety and more avoidance and hostility toward African Americans. Both expectancies and anxiety mediated the relationship between contact quality and avoidance/hostility. Anxiety mediated the expectancy-avoidance/hostility relationship and expectancies mediated the relationship between contact quality and anxiety
(Plant \& Devine, 2003). A similar test of these variables using measures separated by two weeks supported the causal sequence proposed in our model. Contact experiences at Time 1 predicted negative expectancies measured two weeks later and negative expectancies at Time 1 predicted intergroup anxiety measured two weeks later, even when controlling for Time 1 anxiety measure. The reverse was not true, as Time 2 expectations did not predict Time 1 anxiety after controlling for relevant variables (Plant, 2004). Outcome expectancies in both studies reflected a lack of clear behavioral guidelines (e.g. "when interacting with a Black person, I would be unsure of how to act in order to show him or her that I was not prejudiced'). We suggest that perspective taking is central to understanding behavioral guidelines, as lack of understanding of the perspective of African Americans may be a barrier to understanding how to act in interactions with African Americans.

\section{Other mediation effects}

We discussed relationships between contact, perspective taking, and intergroup anxiety on stereotype endorsement and intergroup attitudes as well as the mediating effects of perspective taking in the contact-anxiety relationship in the previous sections. However, several additional relationships exist within our model.

Our model places perspective taking and anxiety in between contact and explicit attitudes and stereotyping. This prediction is consistent with integrated threat theory propositions regarding anxiety, wherein anxiety is a proximal predictor of intergroup attitudes and contact is a distal predictor (W.G Stephan \& Stephan, 2000). In this model, negative contact experiences lead to increased intergroup anxiety that in turn lead to more negative attitudes about the outgroup. This mediational role for anxiety on the contact explicit-attitudes relationship is widely reported (e.g. Corenblum \& Stephan, 2001; Islam \& Hewstone, 1993; Paolini, et al., 2004; C. W. Stephan et al., 2000, Study 3; W. G. Stephan et al., 2002; but see C. W. Stephan et al., 2000, Studies 1 and 2; W. G. Stephan et al., 2000). Though our model places perspective taking between contact and 
explicit attitudes and stereotyping, we view that the importance of perspective taking is in mediating the contact-anxiety relationship. We do not expect perspective taking to mediate relationships between contact and attitudes or stereotypes.

We also propose that anxiety mediates the relationship between perspective taking and explicit attitudes and stereotyping. Several studies found that perspective taking reduced negative attitudes toward outgroups (e.g. Galinsky \& Ku, 2004; Galinsky \& Moskowitz, 2000; Harwood et al., 2005). One explanation for this relationship is that empathy reduces dissimilarity perceptions and feelings of threat (W. G. Stephan \& Finlay, 1999). Indeed, integrated threat theory posits a central role for threats, particularly intergroup anxiety. We propose that perspective taking impacts explicit attitudes and stereotypes by reducing intergroup anxiety. A better understanding of the perspective of outgroup members will impact anxiety when interacting with outgroup members. Thus, anxiety mediates the relationship between perspective taking and explicit attitudes and stereotype endorsement.

\section{Implicit attitudes}

To this point, we have discussed explicit attitudes and stereotypes but not implicit attitudes. Implicit attitudes are commonly defined as automatic social cognitions that are outside of the control of the individual (e.g. Greenwald, McGhee, \& Schwartz, 1998). We discuss two general perspectives on implicit attitudes relevant to predictions regarding contact, perspective taking, and anxiety. The first proposition is that implicit attitudes are one of several components of true attitudes (e.g. Greenwald \& Banaji, 1995). In this view, explicit and implicit measures tap the same target evaluations, albeit in different ways and often with different results. Another view suggests that implicit attitudes reflect environmental associations (Karpinski \& Hilton, 2001). In this view, implicit attitudes reflect the associations the individual has experienced rather than an evaluation of the target. Thus, negative implicit evaluations of African Americans by
Whites from the United States result from immersion in a society with a long history of racial bias (Gehring, Karpinski, \& Hilton, 2003).

\section{Contact and implicit attitudes}

A handful of studies provide insight into how contact affects implicit attitudes. Relevant to contact quality, individuals with close African American friends demonstrated less implicit bias against African Americans than did individuals without close African American friends (Aberson, Shoemaker, \& Tomolillo, 2004). The same finding existed for implicit attitudes toward Hispanics. Friendship provides a context that meets most of the conditions specified in the contact hypothesis (Pettigrew, 1997), suggesting that aspects of contact quantity and quality relate to more favorable implicit attitudes. This effect is apparently not limited to friendships, as participants exhibited less implicit bias toward African Americans in the presence of an African American experimenter than when in the presence of a White experimenter (Lowery, Hardin, \& Sinclair, 2001). Other studies, however, found no relationship between contact quantity and implicit bias. Contact with the elderly was unrelated to implicit bias toward older adults (Jelenec \& Steffens, 2002) and contact with the obese did not influence implicit anti-fat bias (Teachman \& Brownell, 2001).

Several studies examining the impact of counterstereotypical information on implicit attitudes also present data relevant to an environmental association interpretation of implicit attitudes. According to the environmental association model, repeated pairings of outgroup targets with positive stimuli results in positive implicit attitudes. Indeed, exposure to positively valued outgroup targets does reduce implicit bias against the outgroup. Participants exposed to admired African Americans (e.g. Martin Luther King) demonstrated reduced implicit bias toward African Americans (Dasgupta \& Greenwald, 2001) and those instructed to imagine a strong woman evidenced reduced implicit pro-male bias (Blair, Ma, \& Lenton, 2001). Additionally, participants committed fewer errors in stimulus pairings for African American targets after multiple exposures to both stereotype-consistent and 
stereotype-inconsistent information, a strategy the researchers suggest makes race irrelevant (Plant \& Peruche, 2003).

Theoretically, if implicit attitudes result from exposure to societal biases, it follows that positive contact experiences should create more positive implicit attitudes. Exposure to societal biases and contact represent two distinct sources of attitudes. According to an Environmental Association perspective, societal biases are always present and a primary source of negative implicit attitudes toward African Americans. Positive contact experiences exert an opposing effect, producing positive associations with African Americans. In the context of this study, we believe this view implies a direct rather than mediated relationship between contact and implicit attitudes.

\section{Perspective taking and anxiety as predictors of implicit attitudes}

Though there are a handful of studies examining contact impacts on implicit attitudes, relatively few studies examined the impact of perspective taking or anxiety on implicit attitudes. One study demonstrated that students enrolled in diversity education courses evidenced less implicit bias than a control group of students not enrolled in diversity education (Rudman, Ashmore, \& Gary, 2001). Given that diversity education promotes understanding of outgroup perspectives (e.g. Gurin et al., 2004), this suggests that perspective taking may improve implicit attitudes. Though this finding is encouraging, students enrolled in diversity education courses may differ from those who do not choose such a course on a number of potentially relevant dimensions. Another study, examining reactions to overweight people, found mixed results when instructing participants to empathize with the obese. Participants read first person accounts where an overweight protagonist experienced considerable prejudice and social rejection due to her weight. Only those participants who were overweight demonstrated reduced implicit bias following the perspective taking manipulation (Teachman, Gapinski, Brownell, Rawlins, \& Jeyaram, 2003).
Given the limited research in these areas, there is not a firm theoretical basis for predictions regarding the impact of perspective taking and anxiety on implicit attitudes. We suggest that if implicit attitudes are a component of a more general attitude concept (i.e. implicit attitudes as true attitudes) then implicit attitudes relate to the same factors as explicit attitudes. In this view, implicit attitudes should be impacted by perspective taking and anxiety in the same manner as explicit attitudes and stereotypes. Thus, the two perspectives suggest different predictions regarding the effects of contact. As represented in Figure 2, the environmental association model predicts direct effects on implicit attitudes, whereas the true attitudes model suggests mediated effects.

\section{Hypotheses and proposed models}

We put forth several hypotheses concerning the relationships among the variables in our model as specified in Figure 2. Hypotheses 1 through 3 focus on explicit attitudes and stereotypes. Hypotheses 4 and 5 involve implicit attitudes.

Hypothesis 1: Increased contact quantity, quality, and their interaction predict increased perspective taking. The quantity by quality interaction is expected to demonstrate that greater quantity combined with higher quality contact produces the highest levels of perspective taking.

Hypothesis 1a: Perspective taking mediates the relationship between contact and anxiety.

Hypothesis $1 \mathrm{~b}$. Anxiety mediates the relationship between contact and explicit attitudes and stereotyping.

Hypothesis 2: Increased perspective taking relates to reduced anxiety.

Hypothesis 2a: Anxiety mediates the relationship between perspective taking and explicit attitudes and stereotyping.

Hypothesis 3: Reduced anxiety relates to more positive explicit attitudes and reduced stereotyping.

Hypotheses 4 and 5 present competing predictions corresponding to the implicit attitudes 

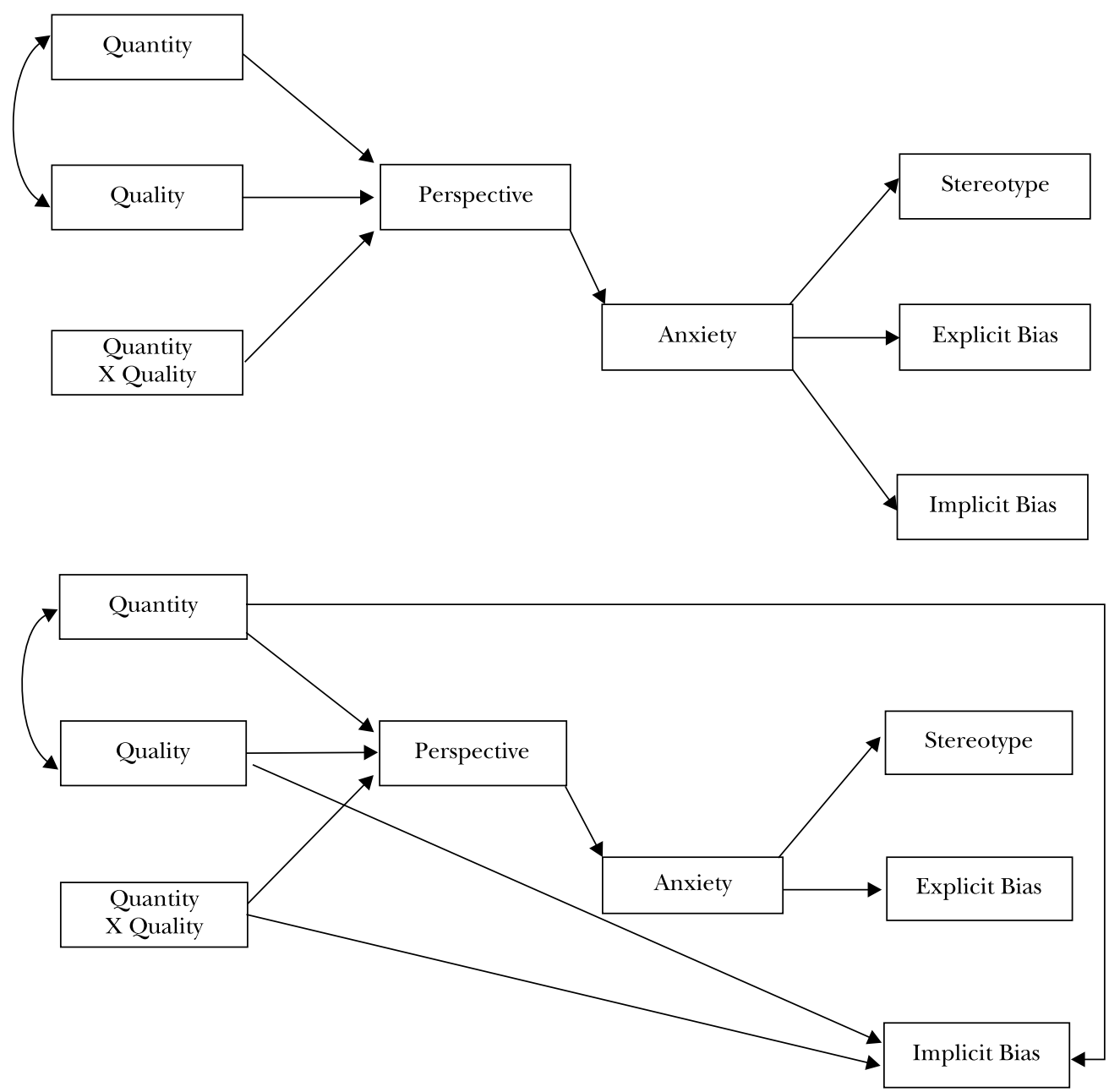

Figure 2. Proposed path models. Upper panel represents the true attitudes model. Lower panel represents the implicit attitudes as environmental association model.

as true attitudes and environmental association arguments outlined above.

Hypothesis 4: The mediators specified in Hypotheses 1a, 1b, and 2a impact implicit attitudes in the same manner as explicit attitudes and stereotyping. This prediction, presented in the top panel of Figure 2, corresponds to the implicit attitudes as true attitudes model.

Hypothesis 5: Greater contact quantity, quality, and their interaction predict more positive implicit attitudes. This hypothesis, presented in the bottom panel of Figure 2, corresponds to an environmental association model of implicit attitudes. Greater quantity combined with higher quality contact should produce the most positive implicit attitudes.

\section{Method}

\section{Participants}

Altogether, 210 undergraduates participated for extra credit or to fulfill research participation 
requirements. Analyses utilized data from only White participants $(n=159)$. We excluded six of these participants due to missing data, leaving a sample of 153 . This sample consisted primarily of women $(80 \%)$ with an average age of $21.0(S D=5.3)$.

\section{Implicit attitudes}

We used Inquisit Software by Millisecond (Inquisit, 2002) to conduct the Implicit Association Test (IAT; Greenwald et al., 1998). Each IAT used 25 White male names (e.g. Adam, Chip), 25 African American male names (e.g. Alonzo, Jamel), 25 pleasant words (e.g. freedom, love), and 25 unpleasant words (e.g. abuse, vomit) as stimuli. Participants engaged in four categorization tasks, labeled as practice and actual trials. Each task required participants to classify a stimulus object into one of two categories. The tasks included distinguishing pleasant and unpleasant words, classifying names as typical of African Americans or Whites, classifying names or words as either 'White or unpleasant' or 'African American or pleasant' (incompatible), and classifying names or words as either 'White or pleasant' or 'African American or unpleasant' (compatible). For each task, there were practice trials. Counterbalancing randomized presentation of categories between the left and right of the screen, and the presentation of compatible and incompatible tasks. Implicit bias against African Americans is an index of differences in reactions to compatible vs. incompatible stimuli.

\section{Self-report measures}

Table 1 presents means, standard deviations, correlations, and reliabilities for each measure where applicable.

Contact Two items addressed contact quantity. Participants indicated the amount of contact experienced with African Americans currently and in the past. Each item comprised an 11-point scale $(0=$ no contact at all to $10=$ daily contact $)$.

Five items, taken from Islam and Hewstone (1993), measured quality of contact. These items asked the participant to think about their closest African American acquaintance and indicate the extent that contact with that person was perceived as equal, involuntary or voluntary, intimate, pleasant, and cooperative. Participants rated each item on an 11-point scale, with the ends of the scale adapted for each item (e.g. $0=$ completely involuntary to $10=$ completely voluntary). Items on this scale correspond to aspects of Allport's (1954) contact hypothesis formulation. The interactions between quantity and quality were computed using the cross product of each centered variable (Aiken \& West, 1991).

Table 1. Descriptive statistics and correlations for predictors and criterion variables

\begin{tabular}{|c|c|c|c|c|c|c|c|c|c|c|}
\hline & $\begin{array}{l}\text { Possible } \\
\text { range }\end{array}$ & $M$ & $S D$ & $\operatorname{Imp}$ & Exp & Anx & Per & St & Quan & Qual \\
\hline Implicit attitudes & $\mathrm{n} / \mathrm{a}$ & 0.5 & 0.4 & .60 & & & & & & \\
\hline Explicit attitudes & 5 to 35 & 11.8 & 4.8 & .01 & .90 & & & & & \\
\hline Anxiety & 0 to 54 & 18.0 & 9.9 & .11 & $.23 * *$ & .88 & & & & \\
\hline Perspective taking & 0 to 54 & 24.2 & 9.9 & .01 & -.05 & $-.39 * *$ & .80 & & & \\
\hline Stereotype endorse & 4 to 40 & 8.8 & 6.6 & .04 & $.46^{* *}$ & $.34 * *$ & $-.16^{*}$ & .91 & & \\
\hline Quantity & 0 to 20 & 12.9 & 5.0 & -.12 & $-.17 *$ & $-.19 *$ & $.26^{* *}$ & -.08 & .59 & \\
\hline Quality & 0 to 50 & 41.3 & 6.8 & -.10 & $-.23 * *$ & $-.27 * *$ & $.23 * *$ & $-.27 * *$ & $.35^{* *}$ & .70 \\
\hline Quantity $\times$ Quality & $\mathrm{n} / \mathrm{a}$ & $\mathrm{n} / \mathrm{a}$ & $\mathrm{n} / \mathrm{a}$ & $.17 *$ & .03 & .06 & .04 & .02 & .05 & .03 \\
\hline
\end{tabular}

$* p<.05 ; * * p<.01$.

Notes: Reliabilities listed on diagonal. Implicit reliability is correlation between odd and even stimulus trials (i.e. split-half). ${ }^{1}$ All other reliability estimates are Cronbach's alpha. $n=153$. Interaction listed as positive correlations. Higher scores on stereotyping, explicit and implicit attitude measures indicate greater bias. Explicit bias and stereotyping range, means, and standard deviations presented as untransformed data. Analyses using these variables utilized square root transformation. 
Though the path analysis technique we present does not typically include interaction terms, the inclusion of interaction in such analyses is a viable analysis strategy (e.g. Kenny \& Judd, 1984; Schumacker \& Marcoulides, 1998).

Perspective taking The measure of perspective taking was a six-item intergroup understanding scale (W. G. Stephan, 2002) containing items such as 'I believe that I have a good understanding of how African American people view the world' and 'I cannot seem to grasp the African American perspective on most issues'. Participants evaluated each item on a 10-point scale $(0=$ strongly disagree to 9 = strongly agree) .

Anxiety The anxiety measure was a modified version of an intergroup anxiety scale (W.G. Stephan \& Stephan, 1985). Six items asked participants how they would feel when interacting with African American people whom they did not know. Participants rated comfort, uncertainty, confidence, awkwardness, anxiety, and feelings of being at ease on a 10 point scale $(0=$ not at all to $9=$ extremely).

Stereotype endorsement We constructed a stereotype endorsement index using four items asking participants to indicate the percentage of African Americans who were hard-working, intelligent, honest, and sincere (adapted from W. G. Stephan et. al, 2002). Participants responded on a 10-point scale $(\mathrm{A}=0-10 \%$, $\mathrm{B}=11-20 \%, \mathrm{C}=21-30 \%, \mathrm{D}=31-40 \%$, $\mathrm{E}=41-50 \%, \mathrm{~F}=51-60 \%, \mathrm{G}=61-70 \%$, $\mathrm{H}=71-80 \%, \mathrm{I}=81-90 \%, \mathrm{~J}=91-100 \%)$. We coded $\mathrm{A}=1, \mathrm{~B}=2$, etc. Scoring reversed items so that higher scores indicated less endorsement of positive stereotypes and higher scores reflected more bias. ${ }^{2}$

We focus on endorsement of positively worded stereotype traits. Changes in the expression of racial prejudice (e.g. Gaertner \& Dovidio, 1981, 1986) include a reluctance to ascribe negative traits to outgroups. Research examining the positive-negative asymmetry effect demonstrates that discrimination is more likely to appear in positive domains such as allocating resources or evaluating outgroup members on positive adjective items (Buhl, 1999).

Explicit attitudes toward African Americans Attitudes toward African Americans consisted of four 7-point semantic differential items. Items included beautiful-ugly, good-bad, pleasantunpleasant, and nice-awful. Higher scores on this index represented more negative attitudes.

\section{Results}

\section{Assumptions, data screening, scoring, and model evaluation criteria}

We used a square root transformation to correct for skew on the explicit attitude and stereotyping measures (Tabachnick \& Fidell, 2001) and then standardized all variables. Following from Greenwald, Nosek, and Banaji's (2003) improved scoring procedures for the IAT, scores consisted of the averaged standardized differences between latencies in the compatible and noncompatible trials. The scoring algorithm uses actual and practice trials. The final measure is a standardized score $(d)$. This scoring algorithm is superior to other procedures in terms of reliability and resistance to methodological influences.

We evaluated each model against the following criteria: a chi-square value producing $p>.05$, a comparative fit index (CFI) value of .95 or above, root mean square error of approximation (RMSEA) of .06 or below, and a standardized root mean square residual (SRMR) of .08 or below (Hu \& Bentler, 1999). We also examined a $90 \%$ confidence interval (CI) around the RMSEA.

\section{Preliminary analyses: correlations and factor analysis}

The zero-order correlations presented in Table 1 provide initial support for several hypotheses. Notable is the significant relationship between the quality by quantity of contact interaction and implicit bias and the nonsignificant correlation between implicit attitudes and stereotype endorsement or explicit attitudes. Also of note was the correlation between explicit attitudes and stereotyping. Given the similarities between the 
stereotype and explicit attitudes measures, we tested the fit of these variables to two orthogonal factors. The orthogonal two-factor solution fit the data well $\left(\chi^{2}(20, N=153)=27.0, p=.14, C F I\right.$ $=.997, R M S E A=.048,90 \%$ CI for RMSEA $=.00$ to $.088, S R M R=.017)$. Next we fit a one-factor model. This model fits the data poorly $\left(\chi^{2}(19\right.$, $N=153)=2046.7, p<.001, C F I=.163, R M S E A=$ $.824,90 \%$ CI for $R M S E A=.792$ to $.852, S R M R=$ $.405)$. Comparing the two models supports the presence of separate constructs as the two-factor model improved fit considerably over the single factor solution $\left(\Delta \chi^{2}(1)=2019.9, p<.001\right)$.

\section{Path models}

In this section, we present tests of the fit of several models. We tested models using EQS with measured variables, as the sample was not large enough to use latent variables. First, we tested the fit of the models represented in Figure 2 then simplified models through addition of paths and deletion of nonsignificant paths. Next, we examined mediation effects. Finally, we tested the fit of three alternative models. To avoid redundancy, we discuss model fit in this section and address tests of hypotheses in the sections that follow.

The first model (Figure 2, top panel) fitted the data poorly $\left(\chi^{2}(20, N=153)=55.2, p<.001\right.$, $C F I=.692, R M S E A=.108,90 \%$ CI for RMSEA $=$ .074 to $.142, S R M R=.100)$. Model fit improved considerably following the addition of a path between the residuals for explicit attitudes and stereotyping (i.e. variables allowed to correlate) $\left(\chi^{2}(19, N=153)=26.1, p=.13, C F I=.938, R M S E A\right.$ $=.050,90 \%$ CI for RMSEA $=.000$ to $.092, S R M R$ $=.077)$. Despite the improved model fit, implicit attitudes were poorly explained $\left(R^{2}=.010\right)$.

The second model (Figure 2, bottom panel) also initially fitted the data poorly $\left(\chi^{2}(18, N=153)\right.$ $=50.3, p<.001, C F I=.717, R M S E A=.109,90 \%$ CI for $R M S E A=.074$ to $.144, S R M R=.094)$. Again fit improved following the addition of a path between explicit attitudes and stereotyping $\left(\chi^{2}(17, N=153)=21.2, p=.22, C F I=\right.$ $.964, R M S E A=.041,90 \%$ CI for RMSEA $=.000$ to $.088, S R M R=.070)$. We judged this model as a better fit to the data due to the marginally better performance on the fit indices and the improved explanation of implicit attitudes $\left(R^{2}=.033\right)$. We next modified this model to further improve fit.

Though the model provided a good initial fit to the data, several paths were not significant. To simplify the model, we deleted $n s$ paths and added a path, suggested by the Lagrange Multiplier Test (Bentler, 1995), between contact quality and anxiety. This model fitted the data well on all indices $\left(\chi^{2}(19, N=153)=17.0, p=.59\right.$, $C F I=1.0, R M S E A=.00,90 \% \mathrm{CI}$ for RMSEA $=.00$ to $.063, S R M R=.056)$. This modification did not significantly impact model fit $\left(\Delta \chi^{2}(2)=4.2\right.$, $p=.12)$. However, we prefer this model as the elimination of $n s$ paths simplifies explanation. This model is summarized in Figure $3 .^{3}$

Finally, we fit a model with paths from each variable to all the variables represented to the right of the variable in the path model (termed All Paths). For example, contact quality predicts perspective taking, anxiety, stereotype endorsement, and attitudes, whereas the perspective taking variable only predicts anxiety, stereotype endorsement, and the two attitude measures. The purpose of this model is to provide mediation tests, as the simplified model does not contain the necessary paths to produce all possible mediation tests. For example, in our final model there is no path from the quantity by quality interaction to perspective taking. Without such a path, mediation is not tested. This model also allows for consideration of additional paths not included in the model. The All Paths model fit the data well $\left(\chi^{2}(2\right.$, $N=153)=0.8, p=.81, C F I=1.0, G F I=.999$, $R M S E A=.00,90 \%$ CI for RMSEA $=.00$ to .123 , $S R M R=.016)$. Though two paths in this model that were not included in the simplified model were significant (quality of contact to explicit attitudes and stereotype endorsement), the addition of paths produced little improvement in model fit over the simplified model $\left(\Delta \chi^{2}(17)\right.$ $=16.2, p=.51)$, suggesting that the simplified model adequately explained the data.

\section{Tests of direct relationships}

This section reports hypothesis tests regarding direct relationships between variables (i.e. non-mediation hypotheses). Results are largely 


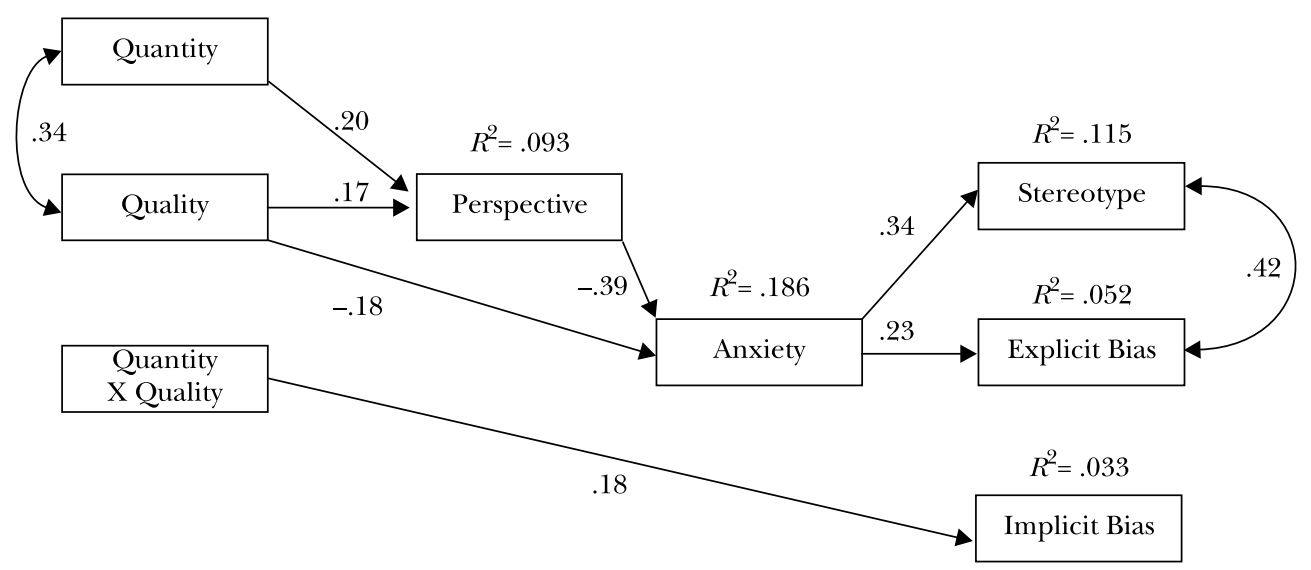

Figure 3. Final path model predicting implicit and explicit attitudes.

consistent with hypotheses regarding explicit attitudes and stereotyping and support the value of the quantity by quality of contact interaction in explaining implicit attitudes.

As shown in Figure 3, the predictors explained $5.2 \%$ of the variance in explicit attitudes, $11.5 \%$ of the variance in stereotype endorsement, and $3.3 \%$ of the variance in implicit attitudes. Partially consistent with Hypothesis 1, contact quality and quantity, but not their interaction, related to increased perspective taking. As predicted in Hypothesis 2, increased perspective taking corresponded to reduced anxiety. However, better quality of contact also related to reduced anxiety. Consistent with Hypothesis 3, reduced anxiety related to lower levels of stereotype endorsement and more positive explicit attitudes.

The only significant predictor of implicit attitudes was the interaction between quality and quantity of contact. To clarify the interaction, we examined correlations between contact quality and implicit attitudes for high and low contact quantity groups as defined by a median split on the quantity variable. In the low contact quantity group $(r(79)=-.25, p=.03)$, better contact quality related to less implicit bias. There was no relationship between quality and implicit attitudes for the high contact quantity group $(r(74)=.10, p=.37)$. The difference between these correlations was significant $(z=2.2, p=.03)$. This result diverges from our predictions regarding the interaction. It seems counterintuitive that contact quality associated positively with more favorable implicit attitudes only when contact quantity was low. However, further examination revealed that the low quantity group $(M=39.7, S D=7.4)$ reported significantly lower contact quality than the high quantity group $(M=43.5, S D=5.5)$, $(t(151)=4.0, p<.001, d=0.64) .{ }^{4}$ This suggests that the high quantity group demonstrated a weaker relationship between quality and implicit attitudes because members of this group reported better overall contact quality (i.e. most of the group experienced high quality contact). That is, participants with higher contact quantity tended to have better contact quality. Since most participants with high quantity also experienced high quality, it may be the case that no relationship between implicit attitudes and quality exists in this group due to the limited variability of quality ratings. This result highlights the importance of contact quality when contact experiences are uncommon.

\section{Mediation}

We used values from the All Paths model to test mediation hypotheses. As we used different path models for these tests, some of the path values differed slightly from those presented in Figure 3. However, these differences do not impact the pattern of results; all significant paths in the simplified model were also significant in the All Paths model. 
This analysis used three estimates derived from EQS (Bentler, 1995) to test for mediation and regression analyses to clarify effects. The first estimate is the total effect of the predictor on the dependent variable. This is analogous to the zero-order correlation. The presence of a total effect indicates a relationship between the predictor and the outcome measure. Early work on mediation analysis argued that the total effect must be significant for mediation to be possible (Baron \& Kenny, 1986). However, more recent work suggests that a significant total effect is not a prerequisite to mediation (Mackinnon, Krull, \& Lockwood, 2000; MacKinnon, Lockwood, Hoffman, West, \& Sheets, 2002; Shrout \& Bolger, 2002). The second estimate is the direct effect of the variable. Direct effects are the path weights. A significant direct effect indicates that the variable makes a significant contribution to prediction within the model. The final estimate is the indirect effect. A significant indirect effect indicates mediation. For the model, we tested mediation on prediction of explicit attitudes, implicit attitudes, stereotype endorsement, and anxiety. These tests are summarized in Table 2.
We predicted that perspective taking mediated the relationship between contact and anxiety (Hypothesis 1a). This hypothesis was supported for contact quality and quantity but not their interaction. This result suggests that frequent and positive contact experiences reduce anxiety through improving perspective taking. Despite the mediation effect, there remained a significant relationship between positive contact quality and reduced anxiety. This relationship is reflected by the inclusion of a direct path from quality of contact to anxiety in our final model.

The only mediated relationship between contact and explicit attitudes or stereotyping was between contact quality and stereotype endorsement. This effect is best termed partial mediation as the direct effect remains significant. However, this statistical result is unclear as both perspective taking and anxiety come between quality of contact and stereotyping. This could indicate mediation by perspective taking or anxiety or both variables jointly. To clarify this effect, we utilized regression to specify the source of mediation, allowing for examination of the mediating role of perspective taking

Table 2. Mediation tested through effect decomposition

\begin{tabular}{|c|c|c|c|c|c|}
\hline Predictor variable & Mediator(s) & $\begin{array}{l}\text { Dependent } \\
\text { Measure }\end{array}$ & Total & Direct & Indirect \\
\hline Quantity contact & PT & Anxiety & -.11 & -.05 & $-.07 *$ \\
\hline Quality contact & PT & & $-.24 *$ & $-.18^{*}$ & $-.06^{\#}$ \\
\hline Quantity $\times$ quality & PT & & .08 & .06 & .02 \\
\hline Quantity contact & PT, Anxiety & Implicit bias & .07 & .07 & .00 \\
\hline Quality contact & PT, Anxiety & & -.04 & -.03 & -.02 \\
\hline Quantity $\times$ quality & PT, Anxiety & & $.18^{*}$ & $.18^{*}$ & .01 \\
\hline Perspective taking & Anxiety & & -.03 & -.07 & .04 \\
\hline Quantity contact & PT, Anxiety & Explicit bias & .10 & .09 & .00 \\
\hline Quality contact & PT, Anxiety & & $.20^{*}$ & $.17 *$ & .03 \\
\hline Quantity $\times$ quality & PT, Anxiety & & .01 & .00 & -.01 \\
\hline Perspective taking & Anxiety & & -.04 & -.10 & $.07 *$ \\
\hline Quantity contact & PT, Anxiety & Stereotype & .01 & .05 & -.04 \\
\hline Quality contact & PT, Anxiety & Endorsement & $-.26 *$ & $-.19 *$ & $-.07 *$ \\
\hline Quantity $\times$ quality & PT, Anxiety & & .02 & -.01 & .02 \\
\hline Perspective taking & Anxiety & & .10 & .01 & $.10^{*}$ \\
\hline
\end{tabular}

$* p<.05 ;{ }^{*} p<.06$.

Note: Significant indirect effects indicate mediation by mediator variables. For attitude and stereotype measures, higher scores indicate more favorable responses. PT = perspective taking. 
and anxiety individually on the quality of the contact-stereotyping relationship, whereas the statistics in Table 2 do not. This analysis follows the basic mediation approach described by Baron and Kenny (1986) with both mediators entered simultaneously (MacKinnon, 2000). When there is a single mediator of relationships, regression follow-up tests are not necessary. This approach demonstrated that perspective taking did not significantly mediate the relationship (Sobel $z=0.0, p=.96)$ and, consistent with Hypothesis $1 \mathrm{~b}$, anxiety did significantly mediate the relationship (Sobel $z=2.5, p=.01$ ). This result suggests that contact reduces stereotype endorsement through anxiety reduction.

Supporting Hypothesis 2a, anxiety mediated the effects of perspective taking on explicit attitudes and stereotyping. This suggests that perspective taking impacts explicit attitudes and stereotyping by reducing intergroup anxiety. ${ }^{5}$

\section{Tests involving alternative models}

The analyses outlined above focused on our proposed model. However, ours is not the only plausible model for these data. Though numerous potential models are possible, we focus on three that are theoretically relevant. It is important to note that for any model, there are many alter- native models that fit the data just as well. In fact, an investigation of published structural equations modeling results demonstrated that equivalent models regularly occur in practice (MacCallum \& Austin, 2000; MacCallum, Wegener, Uchino, \& Fabrigar, 1993).$^{6}$ For each alternative model, we allowed the quality by quantity interaction to correlate with implicit attitudes, as this was the only predictor that was significantly related to implicit attitudes and it would unfairly impact model fit to exclude this path. Additionally, we allowed for quantity and quality to correlate and stereotyping and explicit attitudes to correlate, as in the previous models.

First is a model where anxiety precedes perspective taking. For this model, we reversed the perspective taking and anxiety variables. The fit of this model was worse than the final model represented above $\left(\chi^{2}(19, N=153)=39.6\right.$, $p=.004, C F I=.820, R M S E A=.099,90 \%$ CI for $R M S E A=.047$ to $.121, S R M R=.098)$. Addition of a number of paths to the model (quantity to perspective taking; quantity to explicit attitudes; quality to explicit attitudes; and quality to stereotyping) improved fit considerably $\left(\chi^{2}(15, N=153)=19.4, p=.19, C F I=.961, R M S E A\right.$ $=.044,90 \%$ CI for RMSEA $=.000$ to .093, SRMR $=.060)$. This model, represented in Figure 4,

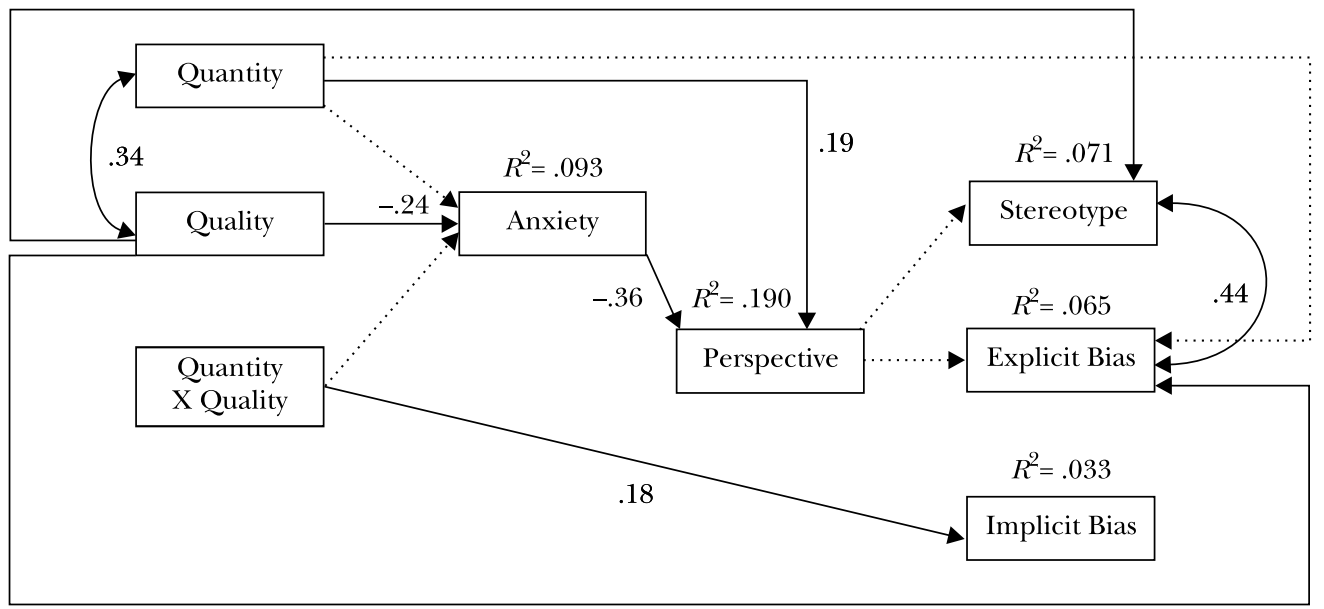

$-.20$

Figure 4. Alternative model placing anxiety before perspective taking.

Dashed lines represent $n s$ paths. 
underperformed our final model on all of the fit indices. Additionally, the model required extensive modifications to improve fit.

Another plausible model allows perspective taking and anxiety to simultaneously mediate the contact-attitudes/stereotyping relationships without the specification of directional paths between the variables. This model, shown in Figure 5, fitted the data poorly $\left(\chi^{2}(15, N=153)=\right.$ $32.6, p=.005, C F I=.846, R M S E A=.088,90 \% \mathrm{CI}$ for $R M S E A=.046$ to $.129, S R M R=.078)$. Results of the Lagrange Multiplier Test did not suggest any path additions that would significantly improve the model. The next model allowed for the correlation of perspective taking and anxiety but was otherwise identical to the previous model.
This model, depicted in Figure 6, fitted the data well $\left(\chi^{2}(14, N=153)=14.7, p=.40, C F I=.994\right.$, $R M S E A=.019,90 \%$ CI for RMSEA $=.00$ to .081 , $S R M R=.056)$. Again, the Lagrange Multiplier Test did not suggest any path additions that would significantly improve the model. The primary difference between this model and our final model is the absence of significant direct or mediated effects for perspective taking. Further, this model performed worse on several indices, particularly the RMSEA. Given the mediated effects of perspective taking and the slightly better fit of our model that included perspective taking as a predictor of anxiety, we suggest that perspective taking adds importantly to the predictions afforded by this alternative model.

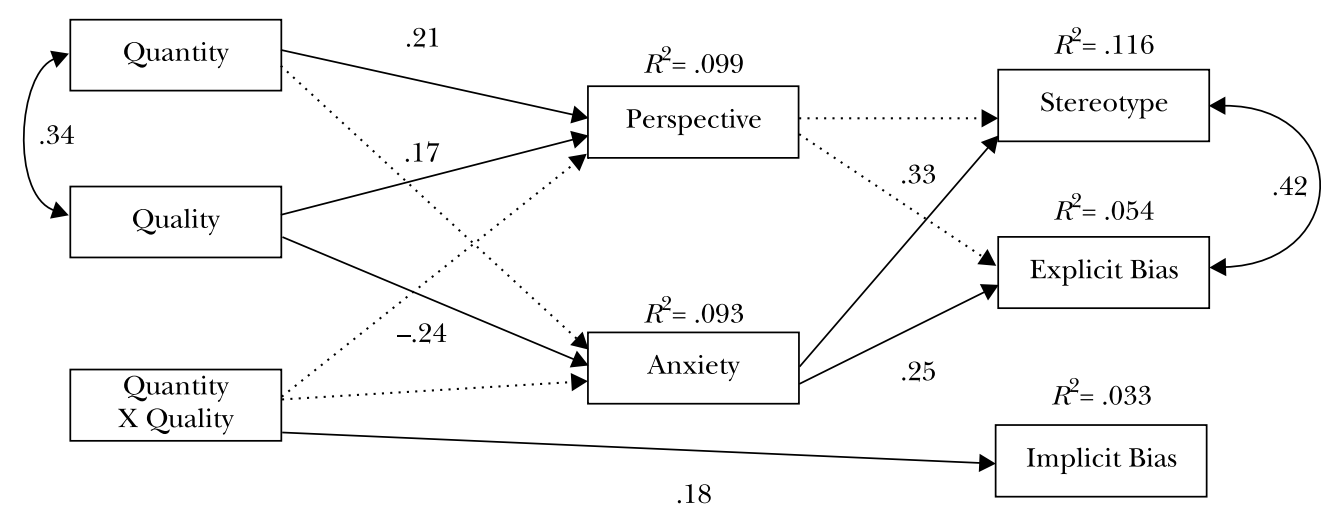

Figure 5. Alternative model with anxiety and perspective taking as mediators of contact-attitudes/stereotypes only. Dashed lines represent $n s$ paths.

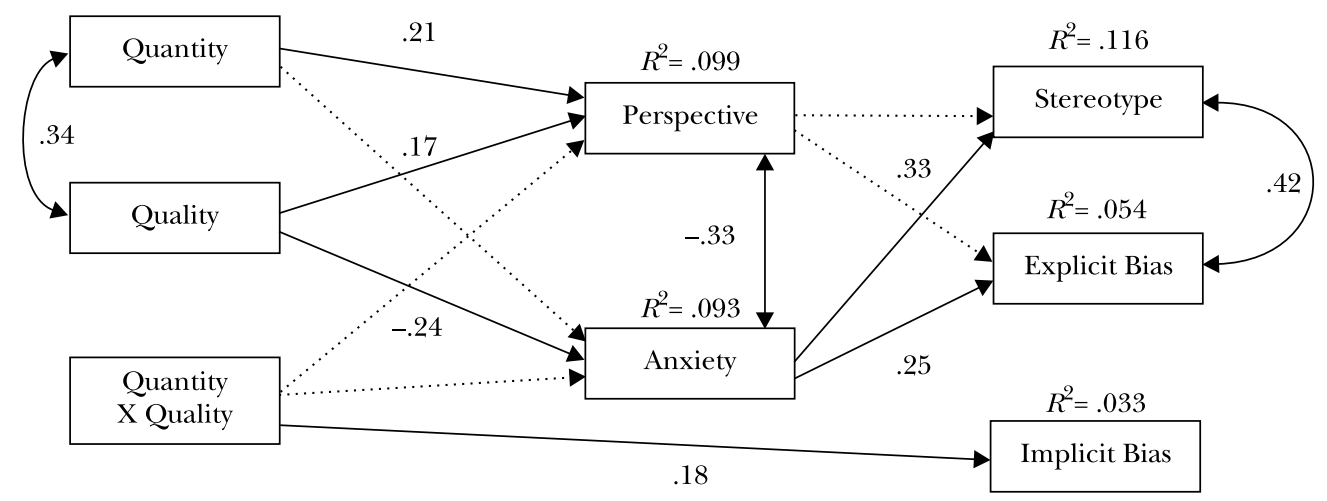

Figure 6. Alternative model correlating anxiety and perspective taking.

Dashed lines represent $n s$ paths. 


\section{Discussion}

We examined several predictors of implicit attitudes, explicit attitudes, and positive stereotype endorsement. Predictors of explicit attitudes and stereotyping were largely consistent with our proposed model. Implicit attitude results supported an environmental association conceptualization of implicit attitudes.

\section{Explicit attitudes and stereotypes}

Better contact quality and increased contact quantity predicted improved perspective taking. This suggests that contact with African Americans improves the ability to understand African American perspectives. Increased perspective taking associated with lessened intergroup anxiety related to African Americans. Most importantly, perspective taking partially mediated the relationships between both contact quality and quantity on anxiety. This finding helps to explain how contact impacts intergroup anxiety, suggesting that perspective taking is central to making contact effective in reducing intergroup anxiety.

Reduced anxiety related to less reluctance to endorse positive stereotypes and more positive explicit attitudes. This result is consistent with research suggesting that anxiety narrows attention and promotes reliance on stereotypes (e.g. Wilder, 1993) and models that propose anxiety is a barrier to positive intergroup attitudes (e.g. W.G. Stephan \& Stephan, 2000). Anxiety mediated the impact of perspective taking on both explicit attitudes and stereotyping, suggesting that perspective taking impacts attitudes and stereotyping by reducing anxiety.

These findings clarify the mechanism by which perspective taking (e.g. Galinsky \& $\mathrm{Ku}$, 2004; Galinsky \& Moskowitz, 2000) improves intergroup attitudes. Perspective taking appears to improve attitudes through an association with reduced anxiety. Clarification of the role of perspective taking adds importantly to integrated threat theory that proposes a direct relationship between contact and anxiety (W. G. Stephan \& Stephan 2000) and models proposing no mediation by perspective taking (e.g. Kenworthy, et al., 2005). The mediational role of perspective taking suggests that contact focused on improving perspective taking may reduce intergroup threats such as anxiety. Findings also clarify the role of perspective taking suggested by research on anxiety (e.g. Easterbrook, 1959). Though several theoretical arguments suggest that anxiety precedes perspective taking, our model where perspective taking predicts anxiety better explained these data.

\section{Implicit attitudes}

Implicit attitude results support an environmental association model interpretation (e.g. Karpinski \& Hilton, 2001). According to this perspective, implicit attitudes reflect individual experiences. This perspective proposes that negative implicit attitudes are a product of exposure to mostly negative representations of African Americans. Our findings indicated that the interaction between contact quality and quantity related to less implicit bias. Whereas several mediation relationships existed for explicit attitudes and stereotyping, there was no mediation of the contact-implicit attitude relationship. Suggesting that both implicit attitudes and explicit attitudes and stereotyping are impacted by contact, but in different manners and possibly by different aspects of contact.

One interpretation afforded by our results is that contact with African Americans serves the role of establishing positive associations with African Americans and that these associations manifest as more positive implicit associations. Experimental results also support this proposition. For example, exposure to admired African Americans (Dasgupta \& Greenwald, 2001), strong women (Blair et al., 2001), and word pairings involving elderly people and positive phrases (e.g. love, happy; Karpinski \& Hilton, 2001, Experiment 3) reduced the strength of implicit biases against each group. We found that for individuals with infrequent contact, high quality contact was especially important. Additionally, more contact related to better contact quality. Though this result may be specific to our sample, it does suggest that contact experiences often lead to positive contact and that as long as contact is not both infrequent and negative, there is a beneficial impact on implicit attitudes. 


\section{Theoretical implications}

Broadly, our results support a dual attitudes conceptualization (e.g. Wilson, Lindsey, \& Schooler, 2000). The dual attitudes model proposes that implicit attitudes are automatic and resistant to change whereas explicit attitudes are purposeful expressions that may override implicit attitudes. This conceptualization explains the common finding of small correlations between implicit and explicit measures as a product of explicit attitudes overriding implicit attitudes (Fazio \& Olson, 2003 but see Cunningham, Preacher, \& Banaji, 2001). As attitudes toward African Americans comprise socially sensitive attitudes, it is reasonable to assume that negative implicit attitudes are usually overridden by more positive explicitly stated attitudes.

The role of contact here is especially important. Positive contact experiences may reduce the need to override negative implicit attitudes. According to the MODE model, motivations and opportunity are necessary to promote deliberative processing (Fazio \& Olson, 2003; Fazio \& Towles-Schwen, 1999). Deliberative processing is the mechanism allowing explicit attitudes to override implicit attitudes. Using this formulation, individuals who possess negative implicit attitudes but express positive explicit attitudes behave either negatively or positively toward African American targets. Motivation and opportunity determine the behavior that occurs. If motivation and opportunity are high (e.g. the individual does not want to appear biased, attention is not limited), behavior corresponds to explicit attitudes and is positive. If motivation and opportunity are limited, behavior corresponds to implicit attitudes and is negative. When individuals experience more contact or better contact quality, their implicit and explicit attitudes are more positive. In this case, motivation and opportunity are less important as both attitudes lead to the same positive behavioral outcomes.

Limitations A primary limitation is the correlational nature of this study. It is unclear whether contact quality and quantity reduce implicit bias or whether individuals who are less implicitly biased are more likely to engage in and have positive contact with outgroup members. Recent longitudinal research suggests that intergroup anxiety serves as an outcome of intergroup contact and predicts future intergroup contact (Levin, van Laar, \& Sidanius, 2003). It is reasonable to assume that perspective taking may have a similar reciprocal relationship with contact.

Several theories propose other factors that predict intergroup attitudes. Other established predictors of attitudes include realistic threats, symbolic threats, ingroup identification, group status (e.g. W. G. Stephan \& Stephan, 2000), and salience of outgroup identity (e.g. Hewstone \& Brown, 1986). These variables may add to and expand our model. Also, we limited our test of environmental associations to contact experiences. There are many other sources of environmental associations such as media exposure that may be unrelated to contact. Further research could expand on our definition of environmental associations and their relationship to implicit bias.

Although we provided a model with several mediation relationships, there is the potential for additional mediation. For example, we proposed that perspective taking mediates the relationship between contact and anxiety. However, factors such as outgroup knowledge (e.g. W. G. Stephan \& Stephan, 2000) could mediate the contactperspective taking relationship and outcome expectancies might mediate the perspective taking-anxiety relationship. Future models might address the most theoretically plausible of these mediation models.

There are several methodological issues. First is the sample size. Most fit indices are underpowered using a sample of 153 with $d f=19$. For the current model, a sample of over roughly 450 participants would be necessary for power of 80\% (MacCallum, Browne, \& Sugawara, 1996). This problem is ameliorated to some extent by the performance of our model on the RMSEA confidence interval and the consistency of the predicted paths with our hypotheses. Another limitation is the sample. Our participants were primarily women, potentially limiting the generalizability of our results. Measures of bias also deserve comment. Implicit attitudes reflect 
differences between positive associations with Whites relative to African Americans. However, our explicit attitude measure examined attitudes toward African Americans in the absence of a comparison group (i.e. not a relative attitude). Future research should include relative explicit attitude measures as well. Finally, the contact quality and quantity measures may also be problematic as quantity focuses on African Americans in general, whereas quality focuses on quality of the participant's relationship with their closest African American acquaintance.

In conclusion, in the current study, we tested models of contact impacts on implicit and explicit attitudes. Although we demonstrated that contact impacts implicit and explicit attitudes differently, it is important to note that contact does impact both forms of bias. This result supports the importance of contact in reducing biases directed toward African Americans and adds to the extensive body of literature supporting the value of contact in improving intergroup attitudes.

\section{Notes}

1. Readers might note the IAT reliability of $r=.60$ is mediocre. This magnitude of correlation is however consistent with other reported uses of the revised scoring algorithm for the IAT. We present the correlation as most studies address IAT reliability in this manner, however we note that using a Cronbach's model for reliability produces $\alpha=.75$.

2. W. G. Stephan and Stephan (2000) suggest that many studies fail to find a relationship between stereotype endorsement and attitudes because they do not measure the valence of stereotypes. We did not include a valence measure but argue that it is not necessary given the stereotypes measured. Participants rated African Americans as hardworking, intelligent, honest, and sincere. Low ratings on these stereotypes would indicate endorsement of negatively valenced characteristics (e.g. lazy, stupid, dishonest, and insincere).

3. Given the mediocre reliability of the quantity of contact variable, we conducted two additional analyses using the simplified model. Analysis 1 used current contact as the quantity variable.
For this analysis the interaction term is current contact by quality. The fit of this model did not differ considerably from the fit of the simplified model $\left(\chi^{2}(19, N=153)=21.3, p=.32\right.$, $C F I=.980, R M S E A=.029,90 \%$ CI for RMSEA $=.000$ to $.078, S R M R=.066)$. Nor did the Wald or Lagrange Multiplier tests suggest deletion or addition of any paths. Analysis 2 used past contact as the quantity variable. For this analysis the interaction term is past contact by quality. The fit of this model did not differ considerably from the fit of the simplified model $\left(\chi^{2}(19\right.$, $N=153)=17.4, p=.56, C F I=1.0, R M S E A=.000$, $90 \%$ CI for RMSEA $=.000$ to $.065, S R M R=.062)$. Again, Wald and Lagrange Multiplier tests did not suggest deletion or addition of any paths.

4. Independent means $t$ test and Cohen's $d$ calculated using transformed variable. Untransformed means reported for interpretability.

5. Results involving the explicit attitude measure suggests a suppression effect for perspective taking. The direct effect of perspective taking was not significant, but it was in a direction opposite that of the indirect effect. Effects that are of different directions suggest the presence of suppression (MacKinnon, et al., 2000). According to these data, increased perspective taking is related to less positive explicitly stated attitudes but it indirectly impacts explicit attitudes positively. The positive indirect relationship indicates that increases in perspective taking lead to reduced anxiety that in turn is related to more positive attitudes. The importance of this result is not clear. However, it does suggest several opportunities for further investigation.

6. Readers might interpret the equivalence of fit between models as evidence that our proposed model is poor. We remind readers that equivalent models are the norm, not the exception. Though few studies present such analyses, the abundance of alternative models is well documented (e.g. MacCallum \& Austin, 2000).

\section{Acknowledgment}

We presented portions of this paper at the Society for Personality and Social Psychology Annual Conferences, Universal City, CA, 2003 and Austin, TX, 2004. 


\section{References}

Aberson, C. L., Shoemaker, C., \& Tomolillo, C. M. (2004). Implicit bias and contact: The role of interethnic friendships. Journal of Social Psychology, 144, 335-347.

Aiken, L. S., \& West, S. G. (1991). Multiple regression: Testing and interpreting interactions. London: Sage.

Allport, G. W. (1954). The nature of prejudice. Reading, MA: Addison-Wesley.

Baron, R., \& Kenny, D. A. (1986). The moderator-mediator variable distinction in social psychological research: Conceptual, strategic, and statistical considerations. Journal of Personality and Social Psychology, 51, 1173-1182.

Batson, R. M., Polycarpou, M. P., Harmon-Jones, E., Imhoff, H. J., Mitchener, E. C., Bednar, L. L. et al. (1997). Empathy and attitudes: Can feelings for a member of a stigmatized group improve feelings toward the group? Journal of Personality and Social Psychology, 72, 105-118.

Bentler, P. M. (1995). EQS: Structural equations program (Version 5.7). Encino, CA: Multivariate Software.

Berrenberg, J. L., Finlay, K. A., Stephan, W. G., \& Stephan, C. W. (2002). Prejudice toward people with cancer or AIDS: Applying the integrated threat model. Journal of Applied Biobehavioral Research, 7, 75-86.

Bizman, A., \& Yinon, Y. (2001). Intergroup and interpersonal threats as determinants of prejudice: The moderating role of in-group identification. Basic and Applied Social Psychology, 23, 191-196.

Black-Gutman, D., \& Hickson, F. (1996). The relationship between racial attitudes and social-cognitive development in children: An Australian study. Developmental Psychology, 32, 448-456.

Blair, I. V., Ma, J. E., \& Lenton, A. P. (2001). Imagining stereotypes away: The moderation of implicit stereotypes through mental imagery. Journal of Personality and Social Psychology, 81, 828-841.

Blascovich, J., Mendes, W. B., Hunter, S. B., Lickel, S. B., \& Kowai-Bell, N. (2001). Perceiver threat in social interactions with stigmatized others. Journal of Personality and Social Psychology, 80, 253-267.

Brown, R., Maras, P., Masser, B., Vivian, J., \& Hewstone, M. (2001). Life on the ocean wave: Testing some intergroup hypotheses in a naturalistic setting. Group Processes $\mathcal{E}$ Intergroup Relations, 4, 81-97.
Buhl, T. (1999). Positive-negative asymmetry in social discrimination: Meta-analytical evidence. Group Processes $\mathcal{E}$ Intergroup Relations, 2, 51-58.

Corenblum, B., \& Stephan, W. G. (2001). White fears and native apprehensions: An integrated threat theory approach to intergroup relations. Canadian Journal of Behavioural Science, 33, 251-268.

Cunningham, W. A., Preacher, K. J., \& Banaji, M. R. (2001). Implicit attitude measures: Consistency, stability, and convergent validity. Psychological Science, 12, 163-170.

Dasgupta, N., \& Greenwald, A. G. (2001). On the malleability of automatic attitudes: Combating automatic prejudice with images of admired and disliked individuals. Journal of Personality and Social Psychology, 81, 800-814.

Davis, M. H. (1994). Empathy: A social psychological approach. Madison, WI: Brown and Benchmark.

Devine, P.G., Evett, S.R., \& Vasquez-Suson, K. (1996). Exploring the interpersonal dynamics of intergroup contact. In R. Sorrentino \& E.T. Higgins (Eds.). Handbook of motivation and cognition: The interpersonal context (Vol. 3, pp. 423-464). New York: Guilford.

Doyle, A. B., \& Aboud, F. E. (1995). A longitudinal study of White children's racial prejudice as a socio-cognitive development. Merrill-Palmer Quarterly, 41, 209-228.

Easterbrook, J. A. (1959). The effect of emotion on the utilization and organization of behaviour. Psychological Review, 66, 183-201.

Fazio, R. H., \& Olson, M. A. (2003). Implicit measures in social cognition research: Their meaning and use. Annual Review of Psychology, 54, 297-327.

Fazio, R. H., \& Towles-Schwen, T. (1999). The MODE model of attitude-behavior processes. In S. Chaiken \& Y. Trope (Eds.), Dual process theories in social psychology (pp. 97-116). New York: Guilford.

Finlay, K. A., \& Stephan, W. G. (2000). Improving intergroup relations: The effects of empathy on racial attitudes. Journal of Applied Social Psychology, 30, 1720-1737.

Fiske, S. T. (2004). Social beings: A core motives approach to social psychology. New York: Wiley.

Gaertner, S. L., \& Dovidio, J. F. (1981). Racism among the well-intentioned. In E. G. Clausen \& J. Bermingham (Eds.), Pluralism, racism, and public policy: The search for equality (pp. 208-222). Boston: G. K. Hall.

Gaertner, S. L., \& Dovidio, J. F. (1986). Prejudice, discrimination, and racism: Historical trends 
and contemporary approaches. In J. F. Dovidio \& S. L. Gaertner (Eds.), Prejudice, discrimination, and racism (pp. 1-34). Orlando, FL: Academic Press.

Galinsky, A. D., \& Ku, G. (2004). The effects of perspective taking on prejudice: The moderating role of self-evaluation. Personality and Social Psychology Bulletin, 30, 599-604.

Galinsky, A. D., \& Moskowitz, G. B. (2000). Perspective taking: Decreasing stereotype expression, stereotype accessibility, and ingroup favoritism. Journal of Personality and Social Psychology, 78, 708-724.

Gerhing, W. J., Karpinski, A., \& Hilton, J. L. (2003). Thinking about interracial interactions. Nature Neuroscience, 6, 1241-1243.

Greenwald, A. G., \& Banaji, M. R. (1995). Implicit social cognition: Attitudes, self-esteem, and stereotypes. Psychological Review, 102, 4-27

Greenwald, A. G., McGhee, D. E., \& Schwartz, J. L. K. (1998). Measuring individual differences in implicit cognition: The Implicit Association Test. Journal of Personality and Social Psychology, 74, 1464-1480.

Greenwald, A. G., Nosek, B. A., \& Banaji, M. R. (2003). Understanding and using the implicit association test: 1. An improved scoring algorithm. Journal of Personality and Social Psychology, 85, 197-216.

Gurin, P. (1999). Expert report of Patricia Gurin. Retrieved July 10, 2003, from http://www.umich. $\mathrm{edu} / \sim \mathrm{urel} / \mathrm{admissions/legal/expert/summ.}$ html.

Gurin, P., Nagda, B. A., \& Lopez, G. E. (2004). The benefits of diversity in education for democratic citizenship. Journal of Social Issues, 60, 17-34.

Harwood, J., Hewstone, M., Paolini, S., \& Voci, A. (2005). Grandparent-grandchild contact and attitudes toward older adults: Moderator and mediator effects. Personality and Social Psychology Bulletin, 31, 393-406.

Hewstone, M. (2002, August). Cross community contact, sectarian attitudes, and forgiveness in Northern Ireland. Paper presented at American Psychological Association, San Francisco, CA.

Hewstone, M., \& Brown, R. (1986). Contact is not enough: An intergroup perspective on the 'contact hypothesis'. In M. Hewstone \& R. Brown (Eds.), Contact and conflict in intergroup encounters (pp. 1-44). Oxford, UK: Basil Blackwell.

Hu, L-T., \& Bentler, P. M. (1999). Cutoff criteria for fit indexes in covariance structure analysis: Conventional criteria versus new alternatives. Structural Equation Modeling, 6, 1-55.
Inquisit 1.29 [Computer software]. (2002). Seattle, WA: Millisecond Software.

Isen, A. M. (1984). Toward understanding the role of affect in cognition. In R. Wyer \& T. Srull (Eds.), Handbook of social cognition (pp. 179-237). Hillsdale, NJ: Erlbaum.

Islam, R. M., \& Hewstone, M. (1993). Dimensions of contact as predictors of intergroup anxiety, perceived out-group variability, and out-group attitude: An integrative model. Personality and Social Psychology Bulletin, 19, 700-710.

Jelenec, P., \& Steffens, M. C. (2002). Implicit attitudes toward elderly women and men. Current Research in Social Psychology, 7, 275-293. Retrieved January 2, 2003 from http://www.uiowa. edu/ grpproc/crisp/crisp.7.16.html.

Johnson, D. W., \& Johnson, R. (1989). Cooperation and competition: Theory and research. Edina, MN: Interaction.

Johnson, D. W., \& Johnson, R. (2000). The three Cs of reducing prejudice and discrimination. In S. Oskamp (Ed.), Reducing prejudice and discrimination (pp.139-268). Mahwah, NJ: Erlbaum.

Karpinski, A., \& Hilton, J. L. (2001). Attitudes and the Implicit Association Test. Journal of Personality and Social Psychology, 81, 774-788.

Kenny, D. A., \& Judd, C. M. (1984). Estimating the nonlinear and interactive effects of latent variables. Psychological Bulletin, 96, 201-210.

Kenworthy, J., Turner, R. N., Hewstone, M., \& Voci, A. (2005). Intergroup contact: When does it work, and why? In J. Dovidio, P. Glick, \& L. Rudman (Eds.), On the nature of prejudice: Fifty years after Allport. Malden, MA: Blackwell.

Levin, S., van Laar, C., \& Sidanius, J. (2003). The effects of ingroup and outgroup friendships on ethnic attitudes in college: A longitudinal study. Group Processes $\mathcal{E}$ Intergroup Relations, 6, 76-92.

Littleford, L. N., Wright, M. O., \& Sayoc-Parial, M. (2005). White student's intergroup anxiety during same-race and interracial interactions: A multimethod approach. Basic and Applied Social Psychology, 27, 85-94.

Lowery, B. S., Hardin, C. D., \& Sinclair, S. (2001). Social influence effects on automatic racial prejudice. Journal of Personality and Social Psychology, 81, 842-855.

MacCallum, R. C., \& Austin, J. T. (2000). Applications of structural equation modeling in psychological research. Annual Review of Psychology, 51, 201-226.

MacCallum, R. C., Browne, M. W., \& Sugawara, H. M. (1996). Power analysis and determination 
of sample size for covariance structure modeling.

Psychological Methods, 1, 130-149.

MacCallum, R. C., Wegener, D. T., Uchino, B. N., \& Fabrigar, L. R. (1993). The problem of equivalent models in applications of covariance structure analysis. Psychological Bulletin, 114, 185-199.

MacKinnon, D. P. (2000). Technical assistance report: Mediation analysis. Retrieved January 20, 2005, from Arizona State University, Research in Prevention Laboratory Web Site http:/ /www. public.asu.edu/ davidpm/ripl/Mediation_ Analysis.PDF.

MacKinnon, D. P., Krull, J. L., \& Lockwood, C. M. (2000). Equivalence of the mediation, confounding, and suppression effects. Prevention Science, 1, 173-181.

MacKinnon, D. P., Lockwood, C. M., Hoffman, J. M., West, S. G., \& Sheets, V. (2002). A comparison of methods to test mediation and other intervening variable effects. Psychological Methods, 7, 83-104.

Nagda, B. A., \& Zúñiga, X. (2003). Fostering meaningful racial engagement through intergroup dialogues. Group Processes $\mathcal{E}$ Intergroup Relations, 6, 111-128.

Paolini, S., Hewstone, M., Cairns, E., \& Voci, A. (2004). Effects of direct and indirect cross-group friendships on judgments of Catholics and Protestants in Northern Ireland: The mediating role of an anxiety-reduction mechanism. Personality and Social Psychology Bulletin, 30, 770-786.

Pettigrew, T. F. (1997). Generalized intergroup contact effects on prejudice. Personality and Social Psychology Bulletin, 23, 173-185.

Pettigrew, T. F. (1998). Intergroup contact theory. Annual Review of Psychology, 49, 65-85.

Pettigrew, T. F., \& Tropp, L. R. (2000). Does intergroup contact reduce prejudice? Recent meta-analytic findings. In S. Oskamp (Ed.), Reducing prejudice and discrimination (pp. 93-114). Mahwah, NJ: Erlbaum.

Plant, E. A. (2004). Responses to interracial interactions over time. Personality and Social Psychology Bulletin, 30, 1458-1471.

Plant, E. A., \& Devine, P. G. (2003). The antecedents and implications of interracial anxiety. Personality and Social Psychology Bulletin, 29, 790-801.

Plant, E. A., \& Peruche, B. M. (2003, February). Reducing implicit bias: Making race irrelevant. Poster session presented at Society for
Personality and Social Psychology, Universal City, CA.

Quintana, S. M., Ybarra, V. C., Gonzalez-Doupe, P., \& De Baessa, Y. (2000). Cross-cultural evaluation of ethnic perspective taking ability: An exploratory investigation with US. Latino and Guatemalan Ladino children. Cultural Diversity and Ethnic Minority Psychology, 6, 334-351.

Richeson, J. A., Baird, A. A., Gordon, H. L., Heatherton, T. F., Wyland, C. L., Trawalter, S. et al. (2003). An fMRI investigation of the impact of interracial contact on executive function. Nature Neuroscience, 6, 1323-1328.

Richeson, J. A., \& Shelton, N. (2003). When prejudice does not pay: Effects of interracial contact on executive function. Psychological Science, 14, 287-290.

Rudman, L. A., Ashmore, R. D., \& Gary, M. L. (2001). 'Unlearning' automatic biases: The malleability of implicit prejudice and stereotypes. Journal of Personality and Social Psychology, 81, 856-868.

Schlenker, B. R., \& Leary, M. R. (1982). Social anxiety and self-presentation: A conceptualization model. Psychological Bulletin, 92, 641-669.

Schumacker, R. E., \& Marcoulides, G. A. (Eds.). (1998). Interaction and nonlinear effects in structural equations modeling. Mahwah, NJ: Erlbaum.

Selman, R. L. (1980). The growth of interpersonal understanding: Developmental and clinical analyses. San Diego, CA: Academic Press.

Shrout, P. E., \& Bolger, N. (2002). Mediation in experimental and nonexperimental studies: New procedures and recommendations. Psychological Methods, 7, 422-445.

Stephan, C. W., Stephan, W. G., Demitrakis, K. M., Yamada, A. M., \& Clason, D. L. (2000). Women's attitudes toward men: An integrated threat theory approach. Psychology of Women Quarterly, 24, 63-73.

Stephan, W. G. (2002). A survey for use in evaluating dialogue programs. Retrieved July 15, 2002 from http://www.westernjustice.org/dialogue_eval_ i.htm.

Stephan, W. G., Boniecki, K. A., Ybarra, O., Bettencourt, A., Ervin, K. S., Jackson, L. A. et al. (2002). The role of threats in racial attitudes of Blacks and Whites. Personality and Social Psychology Bulletin, 28, 1242-1254.

Stephan, W. G., Diaz-Loving, R., \& Duran, A. (2000). Integrated threat theory and 
intercultural attitudes: Mexico and the United States. Journal of Cross-Cultural Psychology, 31, 240-249.

Stephan, W. G., \& Finlay, K. (1999). The role of empathy in improving intergroup relations. Journal of Social Issues, 55, 729-743.

Stephan, W. G., \& Stephan, C. W. (1985) Intergroup anxiety. Journal of Social Issues, 41, 157-176.

Stephan, W. G., \& Stephan, C. W. (2000). An integrated threat theory of prejudice. In

S. Oskamp (Ed.), Reducing prejudice and discrimination (pp. 23-46). Hillsdale, NJ: Erlbaum.

Tabachnick, B. G., \& Fidell, L. S. (2001). Using multivariate statistics (4th ed.). Boston: Allyn \& Bacon.

Teachman, B., \& Brownell, K. D. (2001). Implicit anti-fat bias obese among health professionals: Is anyone immune? International Journal of Obesity, 25, 1-7.

Teachman, B., Gapinski, K. D., Brownell, K. D., Rawlins, M., \& Jeyaram, S. (2003). Demonstration of implicit anti-fat bias: The impact of providing causal information and invoking empathy. Health Psychology, $22,68-78$.

Vescio, T. K., Sechrist, G. B., \& Paolucci, M. P. (2003). Perspective taking and prejudice reduction: The mediational role of empathy arousal and situational attributions. European Journal of Social Psychology, 33, 455-472.

Voci, A., \& Hewstone, M. (2003). Intergroup contact and prejudice toward immigrants in Italy: The mediational role of anxiety and the moderational role of group salience. Group

Processes $\mathcal{E}$ Intergroup Relations, 6, 37-54.

Wilder, D. A. (1993). The role of anxiety in facilitating stereotypic judgments of out-group behavior. In D. M. Mackie \& D. L. Hamilton (Eds.), Affect, cognition, and stereotyping (pp. 87-109). San Diego, CA: Academic Press.

Wilder, D. A., \& Shapiro, P. (1989). Role of competition-induced anxiety in limiting the beneficial impact of positive behavior by an outgroup member. Journal of Personality and Social Psychology, 56, 60-69.

Wilder, D. A., \& Shapiro, P. (1991). Facilitation of outgroup stereotypes by enhanced ingroup identity. Journal of Experimental Social Psychology, 27, 431-452.

Wilson, T. D., Lindsey, S., \& Schooler, T. Y. (2000). A model of dual attitudes. Psychological Review, $107,101-126$.

Paper received 10 June 2004; revised version accepted 18 July 2005.

\section{Biographical notes}

CHRIS ABERSON is currently associate professor of psychology at Humboldt State University. He earned his PhD at the Claremont Graduate University in 1999. His research interests include intergroup relations and interactive tutorials for teaching core statistical concepts.

SARAH HAAG is a counseling psychology $\mathrm{PhD}$ student at the University of Iowa. 